\title{
Fibrin sealants in cardiac surgery: The last five years of their development and application
}

\author{
Robert Novotny ${ }^{1-3, A-D}$, Jaroslav Hlubocký1,2,E, Petr Mitáśs',2, B, , Jaroslav Lindner ${ }^{1,2, E, F}$ \\ ${ }^{1} 2^{\text {nd }}$ Surgical Clinic of Cardiovascular Surgery, General Teaching Hospital, Prague, Czech Republic \\ ${ }^{2} 1$ st Faculty of Medicine, Charles University, Prague, Czech Republic \\ ${ }^{3}$ Transplant Surgery Department, Institute for Clinical and Experimental Medicine, Prague, Czech Republic \\ A - research concept and design; B - collection and/or assembly of data; C - data analysis and interpretation; \\ $D$ - writing the article; $E$ - critical revision of the article; $F$ - final approval of the article
}

Address for correspondence

Robert Novotny

E-mail: novotny_robert@hotmail.com

Funding sources

None declared

Conflict of interest

None declared

Received on July 9, 2016

Reviewed on August 29, 2016

Accepted on February 14, 2017

\begin{abstract}
This review article describes the use of fibrin glue or fibrin sealants and their development over the past 5 years, with a focus on cardiac surgery. The roles of various types of sealants that are available in hemostasis control are reviewed briefly, together with the various potential risks and side effects of their use. The results of experimental work reported during the last 5 years, clinical data from the same period and the safety aspects of fibrin-based glues and sealants are summarized, showing many advantages of their clinical application over the use of synthetic glues or sealants that may be stronger in some cases, but less safe. It can be concluded that the widespread use of fibrin sealants is fully justified, as it benefits the patient as well as the surgeon through the improved control of hemostasis without increasing any adverse effects or complications during surgical procedures.
\end{abstract}

Key words: hemostasis, cardiac surgery, fibrin sealants

D0I

10.17219/acem/68981

\section{Copyright}

Copyright by Author(s)

This is an article distributed under the terms of the

Creative Commons Attribution Non-Commercial License

(http://creativecommons.org/licenses/by-nc-nd/4.0/) 


\section{Introduction}

Sealants were developed in the previous century during World War II, when the need for a fast and reliable method of sealing injuries was obvious. The aim of sealing battle-related injuries was to completely stop bleeding, even with the use of sutures or - to replace the sutures - ligatures or cautery. Sealants are a modern-day auxiliary adjuncts in surgery. ${ }^{1}$ The sealants, including fibrin-based sealants, are studied in approx. 200 scientific and clinical reports each year. ${ }^{2}$ Consequently, it is obvious that the use of sealants in modern-day surgery is of interest for surgeons of various surgical specialties, with the main goal being an improvement in patient care.

\section{The role of sealants in surgery}

Presently, sealants are used in cardiac surgery for several reasons: (a) they help to control hemostasis through the control of bleeding in the area of surgical intervention (as auxiliary sutures, not as suture replacement); (b) they seal the openings made by standard sutures; and (c) they are useful in sealing off the hollow organs of the body. Ideally, they also should (d) improve wound healing and (e) may be useful in the delivery of medication to tissues exposed during surgery. Obviously, the use of sealants in surgery should be simple, safe and well-received by patients. The process of the sealant's disintegration should not cause inflammation or any type of unwanted or pathological process, immunological or other. Moreover, the cost of the use of sealants in surgery should not be prohibitive.

\section{Types of sealant in surgery}

Sealants in surgery may be classified according to various aspects of their production and structure; i.e., based on biological materials (fibrin) or synthetic substances (cyanoacrylates), the number of substances involved in inducing the sealing action, the tediousness of their use, and the safety and cost of various types of sealants.

The main types of sealants and glues used in medicine are as follows: (a) fibrin sealants; (b) cyanoacrylates; (c) gelatin and thrombin-based products; (d) polyethylene glycol polymers; and (e) albumin and glutaraldehyde-based products.

\section{Fibrin sealants}

These are blood-based. They are well-absorbed and easy to use. Their most prevalent use is to control hemostasis in cardiac surgery, liver surgery and after splenic trauma. ${ }^{3,4}$

\section{Cyanoacrylates}

These are synthetic sealants/glues. There are various cyanoacrylates on the market. However, the substances used for medical purposes are $n$-butyl or 2-octyl cyanoacrylate. The bond which is formed is strong enough to make the removal of sutures unnecessary. ${ }^{5,6}$

\section{Gelatin and thrombin-based products}

In principle, these products may be used in many types of surgery. These products (as all other natural/biological products) are relatively non-toxic. ${ }^{7}$

\section{Polyethylene glycol polymers}

These are oligomers or polymers of ethylene oxide and are biodegradable within 6 weeks of their use. They are used mainly in neurosurgery. ${ }^{8,9}$

\section{Albumin and glutaraldehyde-based products}

These mixed-origin products (natural albumin and synthetic glutaraldehyde) have excellent bonding ability in a mere $2-3$ min. ${ }^{10}$ These products are used in cardiac surgery. ${ }^{11}$

\section{Fibrin blood clot formation}

Fibrin plays an essential role in hemostasis. It is a fibrous protein that has an important part in blood clot formation. It is formed through the polymerization of fibrinogen (Factor I of blood coagulation) through an action of the protease enzyme thrombin, formed from prothrombin (Factor II). Additionally, thrombin activates other factors of the blood coagulation cascade, such as Factor V (proaccelerin), Factor VIII (antihemophilic factor) and Factor XIII (transglutaminase). Fibrin and platelets (with thrombin receptors) form a hemostatic clot that should close a natural, pathological or surgery-related tissue wound. ${ }^{12}$

Fibrin originates from fibrinogen, which is a peptide of relatively large molecules (molecular weight: $340 \mathrm{kDa}$ ). It consists of 2 tripeptide units connected at their $N$-terminal regions by disulfide bonds. The aggregation of fibrinogen particles is prevented by charge-charge repulsion. Thrombin cleaves the $N$-terminal structures and makes the resulting fibrin molecules capable of aggregation, resulting in the formation of a "soft" clot that is consequently stabilized by fibrin crosslinking. ${ }^{12}$ Thus, the processes of sealing by fibrin sealants reproduces the final phase of physiological coagulation, the conversion of fibrinogen into fibrin. This whole process is an advantage of fibrin sealants, as it is a process natural to the body. 
The $1^{\text {st }}$ commercially available fibrin sealants to be approved for clinical use in the United States by the Food and Drug Administration (FDA) in 1998 was developed in Europe (TISSEEL; Baxter International Inc., Deerfield, USA). ${ }^{13}$

Fibrin as a biological structure is normally well-tolerated by patients. However, there are a few considerations.

1. The risk of an immunological reaction to animal (bovine) or human proteins present in sealants. It was reported that around $2 \%$ or even $5 \%$ of patients may develop anti-thrombin antibodies. ${ }^{14,15}$

2. The risk of excessive or uncontrolled clotting.

3. The potential (currently very small) for the transmission of some diseases, especially the transmission of some viral pathogens, i.e., human parvovirus B19. ${ }^{16,17}$ Additional concerns for hepatitis B, hepatitis $C$ and HIV transmission are justified. However, such cases have not been reported in the scientific literature. What is important is the fact that this aspect of fibrin sealant use not only threatens patients, but is also potentially risky for the sealanthandling health-care workers.

\section{Recent uses of fibrin-based sealants in cardiac surgery: Experimental work}

Significant scientific work has been done in the area of sealants' suitability and use in surgery. Current studies focus on several aspects of sealant application and on clarifying their possible benefits. The studies from the last 5 years were not only done in a clinical environment, but some were also done under experimental conditions.

Many such experiments compare different types of sealants to obtain information that is not yet available in order to optimize the use of these products. A very important demonstration of not only platelet-rich fibrin-based glue's excellent biocompatibility, but also of the upregulation of neovascularization was shown in experimental conditions using a rat model. ${ }^{18}$ Additionally, aminomethylbenzoic acid prevents or slows down the degradation of fibrin glue. ${ }^{18}$

Recently, the possibility of using a sutureless approach through the application of a fibrin-based hemostat (TachoComb ${ }^{\circledR}$; CSL Behring, Tokyo, Japan) was investigated in experiments on rabbit skin and porcine hearts. ${ }^{19}$ It was found that the adhesive strength of the sealant is significantly increased through the application of polyglycolic acid sheets and fibrin glue together with the sealant. Thus, combining a hemostat with a polyglycolic acid sheet and fibrin glue seems to be a suitable method for difficult clinical situations, such as hemorrhage of the left ventricle. Fibrin glue itself seems to be very suitable for filling the needle holes created during cardiac or vascular surgery. ${ }^{20}$ As much as this use of glue in surgery is obvious, not many studies of glue application for improved hemostasis are available. The report compared different methods of glue application: the drip method, the spray method, the rub and spray method, and the rub and rub method. ${ }^{20}$ A comparison of hole-filling methods has shown that rubbing the fibrin glue onto a hole is the most effective approach. This was also confirmed by microscopic evaluation which documented that needle holes can be effectively clogged by rubbing the glue. ${ }^{20}$ One important finding was documented on the superior effect of fibrin glue compared to a cyanoacrylate-based sealant in experiments using rabbit aortic wall. ${ }^{20}$ The use of a cyanoacrylate-based sealant resulted in thinning of the rabbit aorta, while no such thinning was observed with a fibrinbased sealant. ${ }^{20}$ Additionally, no apoptotic or necrotic cells were found by histological examination of the aortic tissue.

An interesting study devoted to the extraction of endoprostheses implanted in the aorta of experimental pigs was published. ${ }^{21}$ The role of fibrin glue was evaluated in forming the interface between the endoprosthesis and tissue. Fibrin glue between the stent graft and the arterial wall increases the incorporation of the endoprosthesis. ${ }^{21}$

\section{Recent reports on using of fibrin-based sealants in cardiac surgery: Clinical data}

Significantly more reports available in the scientific literature deal with sealants or glues used in clinical situations. We have included only the reports where the use fibrin glue or sealant was described, and omitted reports whose authors used non-fibrin glue or sealant.

A review summarizing the available clinical data from controlled and uncontrolled clinical trials in cardiovascular surgery devoted to the use of various sealants appeared in 2013. ${ }^{22}$ However, it deals with only some of the many products available on the market, mainly the product sold under the name TISSEEL. This review did not raise any concerns regarding the sealants' safety or tolerability, while emphasizing that they provide effective hemostasis control in cardiac and vascular surgery. ${ }^{23}$

The role of bleeding as an important predicting factor in morbidity was analyzed in the report on the use of a sealant in composite aortic root replacement in 56 patients. ${ }^{24}$ The suture line in these operations was sealed with fibrin glue to prevent possible blood leakage. Only 1 patient required surgical re-exploration for bleeding and no case of operative or hospital death appeared. This was attributed to fibrin sealant application (spraying). ${ }^{24}$ In another report, fibrin sealant was reported to have been successfully used in the case of left ventricular rupture, when it was combined with external sutures. ${ }^{25}$

A multicenter, parallel-group, randomized, controlled, open-label Phase II/III study was performed in Italy to address the question of fibrin sealant safety. ${ }^{26}$ Two hundred patients were included in this retrospective 
clinical trial study concentrating on thoracic surgery. Again, no increased risk of any type of adverse effects or surgical complications in relation to the use of fibrin sealant was observed. ${ }^{26}$

An evaluation of the efficacy and cost-effectiveness of a fibrinogen/thrombin-coated collagen patch (TachoSil ${ }^{\circledR}$; CSL Behring, Tokyo, Japan) used for intraoperative hemostasis in patients younger than 16 years with congenital heart disease requiring reoperation during childhood was performed..$^{27}$ The surgeries of 117 patients took place between 2009 and 2011. The reasons for performing reoperations were reinforcement of suture lines, lung lesions, epicardial lesions, and chest wall lesions. A significant association was observed between the use of fibrinogen/ thrombin-coated collagen patch and a decreased need for packed red blood cells. This, with the elimination of the use of other hemostatic or sealant agents, contributed to the decreased cost of the operations. This is important, especially because the patch served as an effective hemostatic agent. ${ }^{28}$ Similar results for the same product were reported for patients who developed lymphatic leakage during an operation for congenital heart disease. The use of fibrinogen/thrombin-coated collagen patch was not only safe, but it also prevented the development of chylothorax during the postoperative period. ${ }^{28}$

A scientific study was published that described the success of using platelet and fibrin glue for a desirable noninvasive treatment of non-healing wounds in the sternal region after a coronary artery bypass operation. ${ }^{29} \mathrm{Six}$ patients were treated for serious, life-threatening chronic sternum wounds with multi-drug-resistant microbial pathogens. The topical application of platelet and fibrin glue every 2 days led to the complete healing of the wound in 5 patients and to significant improvement in 1 patient without any local or systemic complications or any abnormalities in tissue scarring or other type of tissue formation. ${ }^{29}$ However, it was also reported that the use of platelet and fibrin glue sealant may lead to an increased rate of superficial sternal infections. ${ }^{30}$

Fibrin glue may also be successfully applied in cases of gunshot wounds. ${ }^{31}$ It was shown that heart lacerations are successfully healed when mattress sutures with felt strips are covered with fibrin glue. In such cases, the use of fibrin glue contributes to an efficient medical care applied in emergencies.

\section{Safety aspects in using glues or sealants in cardiac surgery}

Fibrin glues or fibrin sealants as such are suitable for use in surgery because of their biological origin. The only unwanted effect that may take place is an immunological reaction. There is no report available to us from the last 5 years indicating some fibrin glue-related problems in cardiac surgery. ${ }^{32}$ It is essential to note that the adhesive strength of fibrin glue or sealant is lower than that of glues based on cyanoacrylate or a gelatin-resorcin-formalin mixture. Lack of reported toxicity resulting from the use of fibrin sealant or glue use in cardiac surgery to repair a dissected aorta is obviously a great advantage over other sealant types, as there are some reports indicating issues with non-fibrin glues or sealants. ${ }^{32}$ For example, there are several reports available on complications related the use of an albumin cross-linked glutaraldehyde glue (BioGlue ${ }^{\circledR}$; CryoLife, Roberts Blvd., Kennesaw, USA). This product was implicated in a case report describing a patient treated for developed stenosis of the saphenous vein and internal thoracic artery bypass grafts. ${ }^{33}$ The fibrotic narrowings which occurred were close to the BioGlue ${ }^{\circledR}$ site of application. The fibrotic reactions were likely associated with a reaction to the glue. Additionally, pulmonary embolism related to the use of BioGlue ${ }^{\circledR}$ was reported in the case of a type A aortic dissection repair. ${ }^{34}$ Additionally, a delayed aorto-pulmonary artery wall disruption with false aneurysm formation after the repair of an acute type of aortic dissection with BioGlue ${ }^{\circledR}$ has also been reported. ${ }^{35}$ There are other reports on BioGlue ${ }^{\circledR}$ -related complications, i.e., a case of ostial left main coronary artery stenosis possibly related to the use of BioGlue ${ }^{\circledR}$ and another report on several patients developing late wound healing problems after the use of BioGlue ${ }^{\circledR}$ for apical hemostasis during transapical aortic valve implantation. ${ }^{36,37}$

\section{Closing remarks on the clinical use of some specific fibrin sealants}

The accumulated data on fibrin-based and other sealants have created the basis for their broad application in practical cardiac surgery applications. In modern surgery, any sealant used in an operating room is of the highest quality and of an approved standard. These sealants are usually approved by the FDA and by other similar administrations in particular countries. The specific applications of some selected sealants are presented for further elucidation of the topic.

TachoSil ${ }^{\mathbb{}}$, according to the FDA, "is a fibrin sealant patch indicated for use with manual compression in adult and pediatric patients as an adjunct to hemostasis in cardiovascular and hepatic surgery, when control of bleeding by standard surgical techniques (such as suture, ligature or cautery) is ineffective or impractical". ${ }^{38}$ In other words, TachoSil ${ }^{\circledR}$ is used in cardiac surgery in situations where the surgical treatment of bleeding is unavailable due to its anatomical location or because it would cause more damage to the anatomical structures. Other examples of TachoSil ${ }^{\mathbb{Q}}$ applications include the repair of a ventricular rupture, a post-infarction repair of a ventricular septal defect and hemostatic support in reoperations. However, it is necessary to emphasize that TachoSil ${ }^{\circledR}$ (and also other sealants) should not be used in place of sutures or other forms of mechanical ligation in the treatment of major arterial or venous bleeding. ${ }^{39-41}$ 
BioGlue $^{\circledR}$, according to the FDA, is indicated as a supporting method for achieving hemostasis in adult patients in the open surgical repair of large vessels. ${ }^{42}$ BioGlue ${ }^{\circledR}$ has a broad spectrum of use in cardiac surgery, such as repair of proximal aortic dissection, aortic root reconstruction procedures, aortic arch reconstruction procedures, ventricular rupture or injury, post-infarction ventricular septal defect repair, and valve repair and replacement procedures. ${ }^{43-48}$ BioGlue ${ }^{\circledR}$ has also shown to be a very effective tool in patients with weakened tissue. ${ }^{49}$

CoSeal ${ }^{\circledR}$ (Baxter International Inc., Deerfield, USA), according to the FDA,is a hydrogel that works as a vascular sealant. ${ }^{50} \mathrm{CoSeal}^{\circledR}$ is indicated for use in reconstructive surgery to achieve adjunctive hemostasis by mechanically sealing leakage. Its main use is in the prevention of adhesions in surgery in high-risk or young patients, where reoperation is expected. Also, CoSeal ${ }^{\circledR}$ is used as either a supplement or an alternative to suture repair, obtaining hemostasis both in high-pressure ventricular repair and in the rupture of a friable coronary sinus adjacent to vital structures. ${ }^{51,52}$

\section{Conclusions}

Based on clinical experience and the results of experimental work, it can be concluded that the widespread use of fibrin sealants is fully justified, as it benefits the patient as well as the surgeon through the improved control of hemostasis while not increasing any adverse effects or complications during surgical procedures.

\section{References}

1. Spotnitz WD. Hemostats, sealants, and adhesives: A practical guide for the surgeon. Am Surg. 2012;78:1305-1321.

2. Spotnitz WD. Fibrin sealant: The only approved hemostat, sealant, and adhesive - a laboratory and clinical perspective. ISRN Surg. 2014;203943. doi: 10.1155/2014/203943

3. Schexneider KI. Fibrin sealants in surgical or traumatic hemorrhage. Curr Opin Hematol. 2004;11:323-326.

4. Kouba E, TornehI C, Lavelle J, Wallen E, Pruthi RS. Partial nephrectomy with fibrin glue repair: Measurement of vascular and pelvicalyceal hydrodynamic bond integrity in a live and abbatoir porcine model. J Urol. 2004;172:326-330.

5. Dalvi AA, Faria MM, Pinto AA. Non-suture closure of wound using cyanoacrylate. J Postgrad Med. 1986;32:97-100. Accessed Junuary 13, 2018.

6. Duvvi SK, Lo S, Kumar R, Spraggs P. Superglue (cyanoacrylate) in the nose. Otolaryngol Head Neck Surg. 2005;133:803-804.

7. Ellegala DB, Maartens NF, Laws ER Jr. Use of FloSeal hemostatic sealant in transsphenoidal pituitary surgery: Technical note. Neurosurgery. 2002;51:513-515.

8. Krause TL, Bittner GD. Rapid morphological fusion of severed myelinated axons by polyethylene glycol. Proc Natl Acad Sci USA. 1990;87:1471-1475.

9. Stavisky RC, Britt JM, Zuzek A, Truong E, Bittner GD. Melatonin enhances the in vitro and in vivo repair of severed rat sciatic axons. Neurosci Lett. 2005;376:98-101.

10. Miscusi M, Polli FM, Forcato $S$, et al. The use of surgical sealants in the repair of dural tears during non-instrumented spinal surgery. Eur Spine J. 2014;23:1761-1766.

11. Bhamidipati CM, Coselli JS, LeMaire SA. BioGlue in 2011: What is its role in cardiac surgery? J Extra Corpor Technol. 2012;44:6-12.
12. Smith TE. Mechanism of blood coagulation. In: Devlin TM, ed. Textbook of Biochemistry with Clinical Correlations. $7^{\text {th }}$ ed. Hoboken, $\mathrm{NJ}$ : John Wiley \& Sons; 2010:1031-1048.

13. Immuno AG. Tisseel ${ }^{\circledR}$ Product Information, 1998. http://www.fda. gov/downloads/biologicsbloodvaccines/bloodbloodproducts/ approvedproducts/licensedproductsblas/fractionatedplasmaproducts/ ucm073008.pdf. Accessed December 20, 2015.

14. Gupta N, Chetter I, Hayes P, et al. Randomized trial of a dry-powder, fibrin sealant in vascular procedures. J Vasc Surg. 2015;62:1288-1295.

15. Verhoef C, Singla N, Moneta G, et al. Fibrocaps for surgical hemostasis: Two randomized, controlled phase II trials. J Surg Res. 2015;194:679-687.

16. Kawamura M, Sawafuji $M$, Watanabe $M$, Horinouchi $H$, Kobayashi K. Frequency of transmission of human parvovirus B19 infection by fibrin sealant used during thoracic surgery. Ann Thorac Surg. 2002;73:1098-1100.

17. Hino $\mathrm{M}$, Ishiko $\mathrm{O}$, Honda $\mathrm{KI}$, et al. Transmission of symptomatic parvovirus B19 infection by fibrin sealant used during surgery. BrJ Haematol. 2000;108:194-195.

18. Wu X, Ren J, Yao G, et al. Biocompatibility, biodegradation, and neovascularization of human single-unit platelet-rich fibrin glue: An in vivo analysis. Chin Med J (Engl). 2014;127:408-411.

19. Kasahara $\mathrm{H}$, Hayashi I. Polyglycolic acid sheet with fibrin glue potentiates the effect of a fibrin-based haemostat in cardiac surgery. J Cardiothorac Surg. 2014;9:121. doi: 10.1186/1749-8090-9-121

20. Kin H, Nakajima T, Okabayashi H. Experimental study on effective application of fibrin glue. Gen Thorac Cardiovasc Surg. 2012;60:140-144.

21. Almeida MJ, Yoshida WB, Hafner L, et al. Biomechanical and histologic analysis in aortic endoprosthesis using fibrin glue. J Vasc Surg. 2011;53:1368-1374.

22. Oda S, Morita S, Tanoue $Y$, Eto M, Matsuda T, Tominaga R. Experimental use of an elastomeric surgical sealant for arterial hemostasis and its long-term tissue response. Interact Cardiovasc Thorac Surg. 2010;10:258-261.

23. Rousou JA. Use of fibrin sealants in cardiovascular surgery: A systematic review. J Card Surg. 2013;28:238-247.

24. Della Corte A, Baldascino F, La Marca F, et al. Hemostatic modifications of the Bentall procedure: Imbricated proximal suture and fibrin sealant reduce postoperative morbidity and mortality rates. Tex Heart Inst J. 2012;39:206-210.

25. Garcia-Villarrea OA, Casillas-Covarrubias LE. Fibrin sealant for left ventricular rupture after mitral valve replacement. Asian Cardiovasc Thorac Ann. 2008;16:152-153.

26. Cardillo G, Carleo F, Carbone L, et al. Adverse effects of fibrin sealants in thoracic surgery. The safety of a new fibrin sealant: Multicenter, randomized, controlled, clinical trial. Eur J Cardiothorac Surg. 2012; 41:657-662.

27. Vida VL, De Franceschi M, Barzon E, Padalino MA, Scattolin F, Stellin G. The use fibrinogen/thrombin-coated equine collagen patch in children requiring reoperations for congenital heart disease: A single center clinical experience. J Cardiovasc Surg (Torino). 2014;55:401-406.

28. Vida VL, Padalino MA, Barzon E, Stellin G. Efficacy of fibrinogen/ thrombin-coated equine collagen patch in controlling lymphatic leaks. J Card Surg. 2012;27:441-442.

29. Tashnizi MA, Alamdari DH, Khayami ME, et al. Treatment of non-healing sternum wound after open-heart surgery with allogenic platelet-rich plasma and fibrin glue-preliminary outcomes. Indian J Plast Surg. 2013;46:538-542.

30. Sakic A, Chevtchik O, Kilo J, et al. Simple adaptations of surgical technique to critically reduce the risk of postoperative sternal complications in patients receiving bilateral internal thoracic arteries. Interact Cardiovasc Thorac Surg. 2013;17:378-382.

31. Suzuki T, Wada T, Funaki S, et al. Traumatic left ventricular free-wall laceration by a gunshot: Report of a case. Surg Today. 2014;44:1152-1155.

32. Suzuki S, Masuda M, Imoto K. The use of surgical glue in acute type A aortic dissection. Gen Thorac Cardiovasc Surg. 2014;62:207-213.

33. Khan H, Chaubey S, Desai J. Early failure of coronary artery bypass grafts: An albumin cross-linked glutaraldehyde (BioGlue) related complication. J Card Surg. 2011;26:264-266. 
34. Rubio Alvarez J, Sierra Quiroga J, Martinez de Alegria A, Delgado Dominguez $C$. Pulmonary embolism due to biological glue after repair of type A aortic dissection. Interact Cardiovasc Thorac Surg. 2011;12:650-651.

35. Alameddine A, Alimov VK, Rousou JA, Freeman J. Aorto-pulmonary artery disruption following acute type-A aortic dissection repair with the use of BioGlue ${ }^{\circledR}$. J Card Surg. 2012;27:371-373.

36. Modi A, Bull R, Tsang G, Kaarne M. Ostial left coronary stenosis following aortic root reconstruction with BioGlue. Interact Cardiovasc Thorac Surg. 2011;13:243-245.

37. Pasic M, Unbehaun A, Drews T, Hetzer R. Late wound healing problems after use of BioGlue for apical hemostasis during transapical aortic valve implantation. Interact Cardiovasc Thorac Surg. 2011;13:532-534.

38. TachoSil. U.S. Food and Drug Administration. https://www.fda.gov/ BiologicsBloodVaccines/BloodBloodProducts/ApprovedProducts/ LicensedProductsBLAs/FractionatedPlasmaProducts/ucm 207482. Accessed March 31, 2010.

39. Feng W, Coady M. Epicardial tachosil patch repair of ventricular rupture in a 90-year-old after mitral valve replacement. Ann Thorac Surg. 2016;101(6):2361-2363.

40. Giordano R, Palma G, Palumbo S, Cioffi S, Russolillo V, Vosa C. Use of biological hemostatic support TachoSil ${ }^{\mathbb{B}}$ for reoperation in pediatric cardiac surgery. Minerva Pediatr. 2016;68(3):240-241.

41. Labrousse L, Barandon L, Choukroun E, Deville C. 'Double patch and glue' technique for early repair of posterior post-infarction ventricular septal defect. Interact Cardiovasc Thorac Surg. 2006;5(3):195-196.

42. BioGlue. U.S. Food and Drug Administration. https://www.accessdata. fda.gov/cdrh_docs/pdf/p010003b.pdf. Accessed December 14, 2001.

43. Zehr KJ. Use of bovine albumin-glutaraldehyde glue in cardiovascular surgery. Ann Thorac Surg. 2007;84:1048-1052.

44. Higashi R, Matsumura Y, Yamaki F. Posterior ventricular septal perforation: Sandwich technique via right ventriculotomy using BioGlue. Gen Thorac Cardiovasc Surg. 2013;61(8):460-462. doi:10.1007/ s11748-012-0172-6

45. Masroor S, Schor J, Carrillo R, Williams DB. Endoventricular pocket repair of type I myocardial rupture after mitral valve replacement: A new technique using pericardial patch, Teflon felt, and BioGlue. Ann Thorac Surg. 2004;77:1439-1441.

46. Dunst KM, Antretter $\mathrm{H}$, Bonatti J. Control of suture hole bleeding after aortic valve replacement by application of BioGlue during circulatory arrest. Int Heart J. 2005;46:175-179.

47. Leva C, Bruno PG, Gallorini C, et al. Complete myocardial revascularization and sutureless technique for left ventricular free wall rupture: Clinical and echocardiographic results. Interact Cardiovasc Thorac Surg. 2006;5:408-412.

48. Durukan AB, Serter FT, Gurbuz HA, Tavlasoglu M, Ucar HI, Yorgancioglu C. Biological glue application in repair of atrioventricular groove rupture: A case report. J Tehran Heart Cent. 2014;9(3):137-139.

49. Gil-Jaurena JM, Aroca Á, Pérez-Caballero R, Pita A. Free wall rupture after arterial switch operation. Ann Thorac Surg. 2014;98(6):22302231. doi:10.1016/j.athoracsur.2014.01.072

50. CoSeal. U.S. Food and Drug Administration. www.accessdata.fda. gov/cdrh_docs/pdf/p010022b.pdf. Accessed February 25, 2002.

51. Pace Napoleone C, Valori A, Crupi G, et al. An observational study of CoSeal for the prevention of adhesions in pediatric cardiac surgery. Interact Cardiovasc Thorac Surg. 2009;9(6):978-982. doi:10.1510/icvts.2009.212175

52. Garcia-Morales LJ, Ramchandani M, Loebe M, Reardon MJ, Bruckner BA, Ramlawi B. Intraoperative surgical sealant application during cardiac defect repair. Tex Heart Inst J. 2014;41(4):440-442. doi:10.14503/THIJ-13-3347 